\title{
Las relaciones internacionales de América Iratina en los escenarios posibles en el largo plazo
}

Nadie discute hoy que América Latina está pasando por la peor crisis que le ha tocado enfrentar en los últimos cincuenta años. Los orígenes de esta crisis son tanto internos como externos, pero, en opinión de muchos, sus raíces fundamentales hay que buscarlas en las violentas perturbaciones registradas en el plano internacional, que anticipan cambios muy profundos en dicho escenario y que, entretanto, crean un agudo clima de confusión e incertidumbre. Estas notas se proponen explorar preliminarmente la dirección a que apuntan las transformaciones que se están produciendo en el escenario internacional a largo plazo.

Tampoco es posible discutir a estas alturas la profundidad de la actual crisis internacional, configurada por un proceso recesivo extraordinariamente grave y prolongado, montado sobre una crisis de carácter estructural. Esta se originó en los países industrializados, a partir de la desintegración del sistema internacional de la postguerra y del quiebre del estilo de desarrollo que se desenvolvió en dichos países durante ese período, al amparo de una determinada estructura del poder mundial. Las discontinuidades o quiebres ya señalados hacen necesario que cualquier análisis acerca de las perspectivas de las relaciones internacionales de los países latinoamericanos en los próximos años deba adoptar una visión prospectiva, esto es, postular de partida los escenarios en que probablemente habrán de desenvolvense esas relaciones en el largo plazo. En nuestra región no hay muchos precedentes al respecto, en parte por la urgencia con que se presentan tantos problemas no resueltos, pero también en parte por nostalgia. Como decía un escritor mexicano, cada vez que los latinoamericanos somos invitados desde el Norte a participar en un foro de carácter prospectjvo, terminamos "acurrucados contra el pasado"1.

*Documento de referencia presentado al Seminario sobre "Las relaciones internacionales de América Latina en los escenarios mundiales de largo plazo" organizado por el RIAL en la CEPAL, Ios días 6 y 7 de mayo de 1983.

"J. A. Lozoya, "Muchos pasados, muchos futuros", en Diálogos No 100, julioagosto de 1981 . 
Esto nos obliga también a mirar hacia afuera, porque el centro dinámico de los cambios que están ocurriendo en el mundo todavía se encuentra en las principales potencias industriales y en los grandes actores transnacionales, cuyo comportamiento debería ser observado atentamente si se quiere anticipar los escenarios en que deberemos movernos en el futuro. Ello implica superar la tradicional costumbre de mirar hacia adentro que tenemos los latinoamericanos. En efecto, con frecuencia tendemos a reemplazar los esfuerzos para buscar a la crisis una salida inédita por una forma de escapismo que consiste en caer en la nostalgia de aquel pasado que mejor concuerda con nuestros propios intereses o con nuestras experiencias positivas. Mucho tiene que ver con esto la inveterada proclividad latinoamericana hacia la ideologia. La ideología es generalmente una forma de proyectar hacia adelante nuestro pasadó preferido. En tal sentido, es la camisa de fuerza del futuro.

Pero es evidente que tendremos que mirar también hasia adentro. La capacidad de respuesta de los países latinoamericanos frente a la actual crisis, especialmente en la medida en que ésta nos enfrenta con un mundo turbulento e incierto, dependerá de nuestra capacidad para utilizar nuestros mercados y recursos internos, para poner en común nuestras potencialidades y para concertar nuestra acción en las negociaciones desarrolladas frente al resto del mundo. Ello, paradojalmente, nos devuelve a la responsabilidad de tomar en cuenta nuestro pasado, no en la forma canónica que le atribuyen nuestras tradicionales ideologias, sino como una realidad capaz de acoger y adoptar lo nuevo. Porque es necesario reconocer que a muchos pasados deben corresponder también muchos futuros.

Es necesario advertir aquí, de partida, que el tratar los problemas que enfrentan los países latinoamericanos en el frente externo desde un punto de vista global presenta grandes riesgos. Estos problemas no pueden ser abordados de un modo uniforme. Sumar realidades tan diferentes como la que presenta América Latina puede llevar a simplificaciones peligrosas. En efecto, la situación de los países latinoamericanos difiere considerablemente $y$, si bien to-dos ellos están pasando por un período crítico, la forma en que se manifiestan los problemas y el peso relativo de cada uno de ellos difiere sensiblemente de país a país, así como también difieren considerablemente sus formas tradicionales de inserción externa. Ello no significa que no existan denominadores comunes que, dentro de ciertos límites, hacen posible y hasta necesario referirse de un modo general a América Latina. Incluso creemos que esta visión de conjunto es condición necesaria para incrementar la capacidad de respuesta de nuestros países frente a la actual crisis.

Estas notas se referirán a los escenarios en que probablemente se desarrollarán las relaciones externas de los países de la región durante los próximos dos decenios, tomando en cuenta tanto (1) el 
estado de las relaciones políticas internacionales como (2) las perspectivas de la economía mundial y (3) la capacidad de concertación regional para enfrentar la crisis.

\section{LA EVOLUCIÓN DEL SISTEMA INTERNACIONAL}

EI sistema internacional, cuyos rasgos fundamentales emergieron de la Segunda Guerra Mundial y perduraron hasta el inicio de los años setenta, experimentó a partir de esa época una completa transformación.

\section{La nueva estructura del poder mundial}

A partir de la época señalada la estructura del poder mundial, que durante todo el período de postguerra permaneció rígidamente jerarquizado dentro de un orden básicamente bipolar, fuertemente influido por la guerrz fría, comenzó a alterarse en forma muy significativa con la declinación relativa del poderío de los Estados Unidos; el surgimiento de tensiones al interior del sistema trilateral $\mathrm{y}$, muy particularmente, de la Alianza Atlántica; las dificultades experimentadas por el bloque soviético y el agotamiento del modelo que éste representaba; el creciente grado de desarrollo y de proyección externa alcanzada por algunos países del Tercer Mundo, y la tendencia -en fin - a la fragmentación del sistema internacional, fenómeno que plantea la necesidad de buscar fórmulas que hagan posible un manejo más colegiado del sistema.

- De acuerdo con la escuela de pensamiento caracterizada bajo el rótulo de la "nueva ortodoxia", el poder de los Estados Unidos en el mundo experimentó una severa declinación durante los años setenta, particularmente frente a la Unión Soviética y al. Medio Oriente, lo que explicaría la preocupación revelada por el hecho de que en 1980 "un $42 \%$ de los ciudadanos estadounidenses indicaron que la política exterior era el problema más importante que enfrentaba su país", dando a ésta una prioridad sustancialmente mayor que a la economía y la energía ${ }^{3}$.

- Paradojalmente, la declinación del poder de los Estados Unidos marcha paralela con el surgimiento de un malestar profundo en el campo socialista. Pese a que el poderío militar soviético se ha incrementado aceleradamente, hasta alcanzar al menos cierta paridad

${ }^{2}$ Asi llamada por Stanley Hoffmann, en "The New York Review of Books", 16 de abril de 1981. Ver a este respecto, por ejemplo, Robert W. Tucker, "The Purposes of American Power", en Foreigni Affairs, vol. 59, № 2 (invierno 1980. 1981) y, anteriormente, "America in Decline: the Foreign Policy of Maturity" en la edición de Foreign Affairs titulada America and the World 1979. Ver también International Institute on Strategic Studies (IISS), "Strategic Survey 1980", publicado en 1981.

'D. Yankelovich y L. Kaagan, "Assertive America", en Foreign Affairs, edición dedicada a America and the World 1980. 
con el de los Estados Unidos, desde un punto de vïsta estructural y de más largo plazo ese incremento no es signo de fortaleza sino de debilidad. La inestabilidad de la presencia soviética en el Tercer Mundo, la invasión de Afganistán (considerada como una medida defensiva que el imperio soviético debió emprender en sus fronteras mismas) y el profundo desafío que representa Polonia para la supervivencia del sistema político y social en que se basa la supervivencia de ese bloque, constituyen interrogantes muy serios que no han sido suficientemente evaluados todavíat. Ellas se agregan a las persistentes dificultades experimentadas por la economía rusa tanto en lo que respecta a su base alimentaria como a la producción y distribución de bienes de consumo durables y a su imperiosa necesidad de adquirir la tecnología occidental5. El modelo soviético como alternativa para la construcción de otras sociedades, particularmente en el Tercer Mundo, parecería estar evaporándose entre la frustración de la población en los países socialistas y la creciente militarización de esos regimenes.

- Las tensiones surgidas al interior del sistema trilateral constituyen otro factor de cambio. Su indicador más reciente radica en los conflictos"surgidos dentro de la Alianza Atlántica. El reemplazo unilateral de la détente por una nueva versión de la política del poder, por parte de los Estados Unidos, ha alienado a sus aliados europeos. Debe recordarse que la détente ha producido resultados positivos para los europeos, tanto en términos económicos como políticos, lo cual es menos claro desde el punto de vista de los Estados Unidos. Además, el globalismo de la política exterior norteamericana es incompatible con la concepción europea, según la cual Ia détente es "divisible" de acuerdo con los temas y regiones que se encuentran en juego. El conflicto generado en torno al pipeline fue una expresión de estas tensiones ${ }^{6}$.

- La emergencia del Tercer Mundo en la palestra mundial, al promediar el período de postguerra, constituye un nuevo factor de inestabilidad y cambio. Hoy este grupo está representado por 120 países, la mitad de los cuales sólo accedió a la independencia durante ese período. Muchos de ellos han alcanzado etapas de desarrollo intermedio y han promovido procesos acelerados de industrialización, integrándose más estrechamente en el sistema interna-

"Ver S. Bialer, "Polland and the Soviet Imperium", en Foreign Affairs, vol. 59, No 3 (1981), asl como también del mismo autor, en compañía de J. Afferica, "Reagan and Russia", en Foreign Affairs, vol. 61, No 2, 1982-1983. Ver también W. G. Hyland, "Clash with the Soviet Union", en Foreign Policy, No 49, 1982.1983.

"Ver "USSR in Crisis: The Failure of an Economic System", por Marshall y Goldman, 1982.

"Ver, por ejemplo, Josef Joffe, "The Enduring Crisis", en Foreign Affairs, vol. 59, No 4, 1981, $y$ "The Long Term Crisis of the Alliance", por Eliot A. Cohen en Foreign Affairs vol. 61 No 2, 1982-83. Ver también David A. Andelman; "Struggle over Western Europe", en Foreign Policy, No 99, 1982-83. 
cional. Ha surgido la Organización de Países no Alineados, el Grupo de los 77 y la OPEP. El punto de vista de las diversas regiones del mundo en desarrollo ha pasado a constituir algo que debe ser tomado en cuenta en el manejo de las relaciones internacionales y los conflictos de origen regional han llegado a tener una gravitación creciente para la estabilidad del mundo en general. Esto último se ve agravado por los intentos efectuados reiteradamente por las grandes potencias para colocar esas situaciones dentro del marco del conflicto Este-Oeste?.

- Los factores señalados más arriba han provocado un fenómeno de "difusión del poder", dando lugar a un mundo más interdependiente, pero también más fragmentado. Han planteado, así, la necesidad de avanzar hacia un manejo colegiado del sistema internacional. Esta nueva estructura del poder mundial plantea a los países en desarrollo $-\mathrm{y}$ muy particularmente a los países latinoamericanosun complejo balance de limitaciones y posibilidades.

\section{La cambiante naturaleza del sistema internacional}

Ya se ha señalado como el mundo que emergió de la postguerra cede paso a un sistema caracterizado por un grado creciente de permisibilidad internacional, con la reconstrucción o el surgimiento de Europa, el Japón y China, con la incorporación a la comunidad internacional de un creciente número de países en desarrollo y con los cambios que -como consecuencia de todo ello- se producen en la estructura del poder mundial. Se transita desde un mundo dominado por consideraciones de seguridad estratégica y por la confrontación entre las dos superpotencias hacia otro caracterizado por un cierto grado de distensión y por una atmósfera más favorable a la prosecución de otros intereses -económicos, tecnológicos, sociales, ecológicos y culturales- en las relaciones entre las naciones. Contribuye a ello la tendencia hacia la fragmentación del poder económico y político mundial. A lo anterior se suma la creciente complejidad y dispersión de los conflictos estratégicos. Este proceso ha sido estimulado también por la emergencia de problemas globales -como la estanflación, el medio ambiente o la energíade cuya solución depende el bienestar de sectores cada vez más amplios de las sociedades nacionales ${ }^{8}$.

"Ver Bertram, "Introduction", en Third World Conflict and International Security, Adelphy Papers, No 166. Ver también, para la región, el $N o 62$ de Estudios Internacionales, consagrado al tema "América Latina después de las Malvinas", octubre-diciembre de 1982.

${ }^{8 E n t r e}$ los trabajos que con mayor anticipación analizaron este fenómeno, en el campo económico, se cuentan los de Richard N. Cooper, "The Economics of Interdependence: Economic Policy in the Atlantic Community", 1968, y "Economic Interdependence and Foreign Policy in the Seventies", en World Politics, vol. 24, No 2, enero de 1972. Un libro fundamental, desde el punto de vista de las relaciones internacionales, en "Power and Interdependence: World Politics in Transition", por Robert O. Keohane Y Joseph S. Nye (1977), así como 
A su vez, estas se transforman. El prolongado período de crecimiento económico, desarrollo social y fortalecimiento democrático que experimentan las sociedades industriales durante la postguerra -y su limitada y precaria transmisión a los países en desarrolloeleva incesantemente el bienestar y promueve el robustecimiento y diversificación de la sociedad civil en esos países. Presionados por ella, los estados nacionales se comprometen con una gama de objetivos cada vez más amplia que, junto a la seguridad nacional, incluye el desarrollo económico, el aumento del ingreso, la defensa del empleo, la preservación del medio ambiente, y la defensa de la identidad cultural y la calidad de la vida de esas sociedades, Estos objetivos pasan a gravitar decisivamente en sus relaciones externas. Al mismo tiempo, conforme la sociedad civil se expande y articula en múltiples grupos de interés, esos grupos aspiran a tomar en sus manos una proporción creciente de los asuntos que interesan a la comunidad. La transferencia de responsabilidades desde el estado hacia la sociedad civil y la consiguiente proliferación de grupos no gubernamentales, en un mundo en que el ejercicio de esas responsabilidades depende cada vez más de la solución que se dé a problemas globales, obliga con frecuencia a estos grupos a buscar la satisfacción de sus intereses en el plano internacional ${ }^{9}$.

Estas tendencias dan origen a un sistema transnacional de nuevo cuño. Emergen nuevos centros de poder mundial. Se fortalecen y diversifican las sociedades nacionales, persiguiendo una gama cada vez más variada de intereses, muchos de los cuales dependen del contexto externo. El estado, a su vez, asume un número cada vez mayor de compromisos, muchos de los cuales también dependen de sus relaciones externas. Se acrecienta la interpenetración entre las distintas sociedades nacionales. La agenda internacional se vuelve menos jerarquizada y más compleja. El estado deja de mono-

la obra editada anteriormente por los mismos autores bajo el tftulo "Transnationals Relations and World Politics" (1972). Entre la literatura sobre el tema,

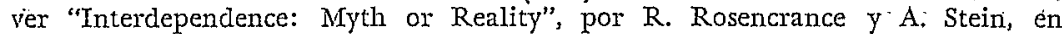
World Politics, vol, 28, No 1, 1976, y los numerosos trabajos sobre el tema publicados por International Organization, como "A Methodology for Design. Research on Interdependence Alternatives", de H. Alker (31-1, 1977); "Whither Interdependence", de R. Rosencrance (31-3, 1977) y "A New International Politics? Diplomacy in Complex Interdependence", de K. J. Holstie (32-2. 1977). Algunos de estos trabajos, junto con otros, se reúnen en "Globalism versus Realism: International Relations' Third Debate", editado por R. Maghroosi y B. Ramberg, 1982. Ver, por último, J. N. Rosenau, "The Study of Global Interdependence: Essays on the Transnationalization of World Affairs", 1980.

"Ver OCDE, "The Welfare State in Crisis", 1981, y L. Thurow, "The Zero.Sum. Society: Distribution and the Possibilities for Economic Change. Desde un ángulo latinoamericano, ver F. H. Cardoso, "Las Polfticas Sociales en la década del 80: nuevas opciones", ILPES/UNICEF, 1982, asi como también los trabajos reunidos en el No 6 de Gritica y Utopía, bajo el título "Sociedad Civil y Autoritarismo", particularmente el de A. Flisfisch, "Notas acerca del reforzamiento de la Sociedad Civil". 
polizar el manejo de las relaciones externas y nuevos agentes comienzan a intervenir en ellas poniendo en juego recursos de poder no tradicionales.

Estos elementos permiten reconstruir la estructura y el funcionamiento de numerosos "circuitos" que operan en torno a la agenda, los agentes y los recursos de poder señalados más arriba, y que vinculan de múltiples maneras a las distintas sociedades nacionales en función de intereses especificos. Desde esta penspectiva, sería posible postular el surgimiento de circuitos transnacionalizados en el campo energético, alimentario, indusrial, tecnológico, financiero, estratégico, científico y cultural. Gada uno de estos circuitos presenta un considerable grado de especificidad propia. Las condiciones de acceso de los distintos páses a cada uno de ellos, y su posición relativa dentro del circuito, no depende exclusivamente de su ubicación dentro de la jerarquía internacional (ya sea dentro del conflicto Este-Oeste o de las relaciones Norte-Sur) sino de su posición respecto de los intereses que en cada caso se encuentran en juego ${ }^{10}$.

La estructura internacional se vuelve más fluida e interdependiente pero, paradojalmente, también más fragmentada y más incierta. La crisis del estilo de desarrolo prevaleciente en los países industriales, a que se hará referencia más adelante, tiende a acentuar estas tendencias. Creemos que este escenario se mantendrá y aún habrá de acentuanse en el futuro. Dentro de él, los países en desarrollo $-y$, muy particularmente los países latinoamericanos, en la medida en que han alcanzado un mayor grado de integración en el sistema internacional - verán agudizarse su vulnerabilidad externa pero, al mismo tiempo, ensancharse su margen de maniobra, enfrentando un complejo balance de riesgos y oportunidades, que será necesario evaluar con más lucidez que en el pasado para formular su estrategia externa.

\section{La gobernabilidad del nuevo orden mundial}

El mundo que surgió de la postguerra logró contar con un cierto "orden internacional" impuesto por las grandes potencias mediante la política del poder. Ese remedio de "orden mundial", basa-

${ }^{30}$ Este concepto ha sido analizado por un grupo de trabajo del RIAL (Programa Latinoamericano de Relaciones Internacionales) sobre Interdependencia $y$ Desarrollo Nacional. El autor publicó un trabajo, bajo el mismo título, en Estudios Internacionales $N$ \% 58, abril-junio de 1982, seguido de "La Transnacionalización Económica versus la Autonomía de las Políticas Nacionales", por M. Dias David, en Estudios Internacionales $N 959$. En el No 64 de la misma revista aparecerá un conjunto de trabajos de Rosario Green, R. Bouzas, J. G. Valdés, A. Varas y L. Tomassini sobre esta problemática. Ver, asimismo, K. R. Mirow y H. Maurer, "Webs of Power: International Cartels and the World Economy", 1981 con una interesante referencia inicial a Brasil). 
do en la fuerza, se ha desintegrado sin haber sido sustituido por uno nuevo. Estos cambios plantean interrogantes acerca de la gobernabilidad del nuevo sistema internacional en formación ${ }^{11}$.

- Uno de esos interrogantes se refiere a la posibilidad de resolver problemas que por su naturaleza son globales a través de políticas y soluciones racionales, como ocurre hoy día, y a la conveniencia de buscar mecanismos que permitan el manejo colectivo de los más importantes asuntos internacionales.

- También habrá que compatibilizar la necesidad de contar con mecanismos multilaterales, que permitan un manejo colectivo de los problemas que enfrentan un mundo interdependiente en que los países en desarrollo están cada vez más integrados, con la preservación de márgenes aceptables de autonomía nacional para este último tipo de países.

- Otro problema consiste en cómo asegurar una participación orgánica y eficaz a los sectores no gubernamentales, que han pasado a tener una importancia creciente en la vida internacional contemporánea y de los cuales depende en parte la respuesta de muchos de los problemas globales que la caracterizan, en el manejo de las relaciones internacionales.

- La dimensión regional habrá de tener un papel cada vez más decisivo en la formulación de los mecanismos y políticas que se diseñen para manejar los asuntos internacionales, particularmente tratándose de las regiones del mundo en desarrollo, que poseen un historial rico en experiencias y realizaciones, han creado organizaciones propias y han ido definiendo posiciones en los foros internacionales.

- El desafío más importante consistirá en construir -tomando en cuenta los elementos anteriormente mencionados- un nuevo "orden mundial" estable y justo que reemplace el que surgió de la postguerra y que hoy se ha desintegrado.

Todo indica que el orden de postguerra no se reconstituirá en los próximos decenios y que surgirán proyectos alternativos para establecer un nuevo "orden mundial" que asegure un mínimo de moderación, progreso, estabilidad, justicia y paz a las naciones. Ello será escencial si se considera que la "imprevisibilidad" probablemente continuará constituyendo un factor desconcertante y duradero en las relaciones internacionales ${ }^{12}$.

${ }^{11}$ El Aspen Institute for Humanistic Studies se ha dirigido a algunos de cstos interrogantes en el estudio titulado "Governance in the Western Hemisphere" y en los documentos que le sirvieron de base, los que fueron publicados en Washington, en 1982.

"Sobre este concepto ver Allan Goodman, "The Unexpected an the International System", en "The Governance of the Western Hemisphere", op. cit., background papers, 1982. 


\section{LA GRISTS DE LA ECONOMÍA MUNDIAT}

El estilo de desarrollo prevaleciente en la postguerra, basado en la ideología del crecimiento y la modernización y en la proyección global de ese modelo a través del efecto de demostración provocado por las corporaciones transnacionales y por todo el aparataje institucional que les sirvió de sustento, fue posibilitado por la estructura internacional imperante durante ese periodo. Dicha estructura se caracterizó por la hegemonía de los Estados Unidos y por el predominio de consideraciones centradas en torno al mantenimiento de la seguridad estratégica de esa nación y de los demás países con los cuales ésta había entrado en compromisos defensivos, dentro del esquema de la guerra fría, e hizo posible la expansión de un estilo de desarrollo que por una parte expresaba y por la otra promovía los intereses de los Estados Unidos y de sus principales aliados. Junto con modificarse la estructura internacional, fracasó también el proyecto encaminado a difundir el estilo de desarrollo anteriormente señalado en sus variables fundamentales.

De allí que, a partir de los años 1970, la economía mundial haya entrado en una profunda crisis, cuyo carácter estructural (y no meramente cíclico) ya nadie discute, crisis que ha golpeado severamente al mundo en desarrollo, particularmente a los países latinoamericanos, que habian alcanzado un mayor grado de integración en la economía internacional.

Nuestra hipótesis apunta a que el núcleo de esta situación se encuentra en la crisis industrial que enfrentan los países industrializados del Oeste, y en sus consecuencias en relación con el Este y con el Sur, sin olvidar por ello la base ecológica ni el síndrome financiero que rodean las crisis.

\section{La crisis industrial y sus causas profurudas}

"La crisis de la economía mundial es ante todo una crisis industrial". Así comienza el más reciente informe prospectivo sobre la economía mundial elaborado desde una perspectiva europea. "Sin duda las sucesivas conmociones petroleras han contribuido poderosamente a desestabilizar las economías nacionales así como también los intercambios internacionales. Sin duda, del mismo modo, es necesario piestar una atención sostenida a las tensiones monetarias derivadas de la ruptura ocurrida en 1979, la cual ha marcado un completo viraje en relación con la tendencia surgida a partir de 1971. Pero si hoy resulta indispensable conjurar los riesgos monetarios tanto como ayer los desequilibrios energéticos, es dentro de la industria donde se encuentran los orígenes más profundos de la crisis y los más destacados perfiles que se advierten en el horizonte de 1990"13.

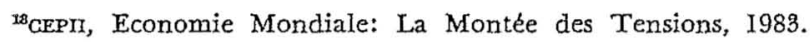


Se podrá discutir si el debilitamiento del impulso industrial que se observa en los últimos años en la mayor parte de los países desarrollados responde a una tendencia irreversible hacia una "sociedad postindustrial". o si sólo se debe a las naturales resistencias para encarar una reestructuración de ese sector, realizada la cual el sector secundario volverá a convertirse en el motor del crecimiento económico y a garantizar la difusión de los cambios estructurales que fueren necesarios en esas sociedades. Se podrá discutir también si la economía mundial ha entrado por largo tiempo en un período de crecimiento lento o si la rápida incorporación de los cambios tecnológicos que ya se encuentran en curso determinará una nueva era de dinamismo y de progreso. Se podrá asignar distinto peso a la importancia de las limitaciones provenientes del lado de la oferta de energía y recursos naturales o asumir actitudes más o menos optimistas con respecto a la potencialidad que encierran los desarrollos tecnológicos recientes en relación con la energía y la producción de nuevos materiales. Gualesquiera sean los vaticinios que se hagan sobre estas materias, queda en pie la profundidad de la transformación que está experimentando la industria mundial y la importancia de los reecientes avances tecnológicos, junto con la impresión de que la humanidad está entrando en una "segunda revolución industrial". De allí que todo intento por diseñar los escenarios en que se desenvolverá la economía mundial a largo plazo deba centrarse en el proceso de reestructuración industrial que se encuentra en marcha y en sus causas: el quiebre del estilo de desarroIlo que predominó durante la postguerra.

El extraordinario aumento que experimentó el comercio internacional en la postguerra se debió fundamentalmente a que la expansión de la demanda por aquellos bienes de consumo durable que hicieron posible la implantación de la "american way of life" -y su difusión global- fue satisfecha mediante el incremento de la especialización entre los países industriales, de conformidad con los principios ricardianos. De esta manera, cada país adquirió una posición dominante en el mercado en determinados productos o sectores industriales, situación que favoreció el aumento incesante de los precios.

Esto último, junto con la reconstrucción de Europa y el surgimiento del Japón como grandes potencias industriales, estimuló la competencia y la transformación del espectro de especializaciones ya adquiridas por los distintos países, no sólo entre diversas ramas industriales sino también, y en forma mucho más fina, al interior de cada una de ellas. Al mismo tiempo, la expansión de la demanda de bienes durables, que había constituido la base del desarrollo de las industrias más dinámicas durante la postguerra, comenzó a curvarse a fines de los años sesenta, siendo reemplazada por una sensible contracción y por un cambio en la compósición de la mis- 
ma, como consecuencia de la saturación de los mercados de ese tipo de productos, en cuya expansión e integración se había basado el auge precedente.

El proceso de transnacionalización, que facilitó la expansión del estilo de desarrollo prevaleciente en la postguerra y de los correspondiente patrones de producción y de consumo, también facilitó los cambios que más tarde ocurrieron en la estructura de los mercados y en la organización que comenzó a adoptar la producción mundial para adaptarse a ellos.

Tiende a surgir así una nueva división internacional del trabajo, cuyo esquema futuro no se vislumbra claramente todavía, pero que ya está provocando fuertes tensiones entre los países desarrollados y podría alterar las formas tradicionales de inserción de los países en desarrollo en la economía mundial. En el Norte estas tensiones se manifiestan en la relativa declinación del poderío industrial de los Estados Unidos en comparación con el de Europa y, muy particularmente, el del Japón. Se manifiestan también en el lento y desigual crecimiento de la productividad, las inversiones, la rentabilidad de las empresas y el ritmo de innovación tecnológica, así como en el aumento de la capacidad ociosa en Ias industrias tradicionales -que constituyeron el motor del crecimiento en la postguerra- vis a vis a otras ramas tecnológicamente más avanzadas ${ }^{14}$.

Por otra parte, se va poniendo de manifiesto poco a poco que la crisis en Ios países industrializados hunde sus raíces en problemas de carácter socio-cultural. En el plano social, la creciente alienación que experimentan individuos y grupos al interior de las sociedades industriales, como consecuencia de la producción en escala y el consumo de masas provoca la búsqueda de "raíces", estimulando una incesante proliferación de agrupaciones y una creciente articulación de la sociedad civil. El prolongado período de crecimiento económico, desarrollo social y participación democrática de que disfrutaron esas sociedades durante la postguerra favorecieron poderosamente este fenómeno al elevar incesantemente el bienestar y promover la diversificación de esas sociedades. Los nuevos grupos sociales persiguen una gama cada vez más amplia de objetivos que,

${ }^{11} \mathrm{Al}$ respecto, ver entre otros trabajos, B. Evers et al., "Perspectives on industrial adjustment: the EEC and the developing countries", 1977; S. Mukherjee, "Restructuration des Economies Industrielles et Commerce avec les Pays en Development", 1979, y J. Grunwald. "El Comercio Intraindustrial Norte-Sur: compartiendo la producción industrial entre los países desarrollaclos y en desarrollo", en Estudios Internacionales No 48; octubre-diciembre de 1979. Ver también, F. Fröbel et al., "La nueva división internacional del trabajo: paro estructural en los países industrializados e industrialización en los páses en desarro11o", 1980. Es fundamental el informe de la ocDE, "Facing the Future", 1979, y el informe del cepri ya citado. Desde un ángulo latinoamericano, ver J. Villa. nueva, "Perspectivas del desarrollo industrial latinoamericano: una completa transformación", 1978, y F. Fajnaylber, "Dinámica industrial en las economfas avanzadas y en los países semi-industrializados", en donde se encontrará un punto de vista diferente. 
junto con el resguardo de la seguridad y el incremento del ingreso, incluyen la búsqueda de una distribución más igualitaria de la riqueza, la diversificación de las ocupaciones, el ejercicio de profesiones más creativas, el arraigo en una comunidad local, Ia preservación del medio ambitonte, la identidad cultural y la calidad de la vida en sus diversos aspectos. La fuerza de trabajo se vuelve más diversificada y cada uno de los segmentos en que se desdobla desarrolla preferencias especificas. La mujer se incorpora al trabajo y a la vida pública, la educación se torna permanente, las barreras entre estudiantes y trabajador se desdibujan, y cada profesional puede reciclarse varias reces ${ }^{\mathbf{1 5}}$.

Todo ello se expresa, en el plano político, en un fuerte contrapunto en torno al papel relativo de la sociedad civil y del estado. Un simposium reciente organizado por la ocDe señalaba: "De la naturaleza de las necesidades y aspiraciones sociales emergentes en las sociedades post-industriales contemporáneas fluye la necesidad de buscar nuevas relaciones entre la acción del estado y la acción privada; de promover el surgimiento de nuevos agentes de bienestar frente a ellos mismos y a los demás. Es en este sentido que la emergencia de una sociedad del bienestar es al mismo tiempo inevitable y deseable", en contraposición con el "estado benefactor" que predominara en el pasado ${ }^{16}$.

Una última categoría de factores que está incidiendo en la transformación y crisis del estilo prevaleciente de desarrollo se refiere a la profunda mutación de los valores o preferencias que está experimentando un número creciente de grupos y sectores al interior de las sociedades avanzadas. Desde la sociedad "postindustrial" de Daniel Bell hasta la sociedad "hecha a la medida" que podría suceder a la era de producción en masa de Alvin Toffler, pasando por el ataque al gigantismo lanzado en nombre del slogan "small is beautiful" por E. S. Schumacher; son numerosas las imágenes que las ciencias sociales de los países nórdicos nos ofrecen para interpretar su transición y crisis ${ }^{17}$. Según el informe de la OCDE antes citado, esa transición se expresaría en el reemplazo de un conjunto de valores materialistas por otros de carácter post-materialistas, que giran en torno a preferencias vinculadas con la calidad de la vida. En esta transformación de los valores radica probablemente la fuerza de cambio más poderosa de la civilización industrial a largo plazo -y una de las pocas fuerzas de cambio en que los pafses en desarro1lo, lejos de ser excluidos, podrían desempeñar un papel protagó-

${ }^{10} \mathrm{OCDE}$, "Facing the Future", 1979.

${ }^{18} \mathrm{OCDE}$, "The Welfare State in Crisis", op. cit. Ver J. M. Echavarría, "Apuntes acerca del futuro de las democracias occidentales", en revista de la CEPAL Ni 4, segundo semestre de 1977 .

17. Bell, "The Coming of the Post-Industrial Society", 1973, y "The Cul. tural Contradictions of Capitalism", 1976; E. F. Schumacher, "Small is Beautiful", 1973; A. Toffler, "The Third Wave". 1980. 
nico. Los factores políticos y socioculturales anteriormente señalados son, en última instancia, el caldo de cultivo donde se insertan los gérmenes que están transformando la estructura económica internacional. Las tendencias anteriormente señaladas determinan que las relaciones Norte-Sur - sin superar su estructural asimetríase vuelvan menos unívocas, más complejas y más interdependientes. La participación de las manufacturas en las exportaciones totales de los países en desarrollo se ha ido ampliando desde el 10\% en 1955, al 20\% diez años más tarde y al $40 \%$ en 1975 . Ellas representarán más de la mitad de las exportaciones globales del tercer mundo al promediar el presente decenio. Por eso, para Sir Arthur Lewis, "La división del mundo entre países en desarrollo que exportan productos agrícolas e importan manufacturas, y países desarrollados que hacen lo contrario, está en vías de desaparecer"18. Esto implica el recrudecimiento del proteccionismo y las nuevas modalidades que ha adoptado este fenómeno en los países industrializados. Pese al impacto fuertemente negativo de este fenómeno sobre las exportaciones de los países en desarrollo, hay una diferencia sustancial entre esta situación y aquella en que dichos países se encontraban a comienzos de la postguerra, cuando simplemente no estaban en condiciones de exportar manufacturas. Detrás del "velo proteccionista" levantado por los países industrializados se encuentra su pérdida de capacidad competitiva en un creciente número de ramas industriales. En tal sentido, resulta adverso a los intereses de los propios países avanzados y debería constituir un fenómeno esencialmente transitorio, no sólo porque tiende a postergar el ajuste de sus economías, sino porque limita la expansión de los ingresos y, por consiguiente, de los mercados de los países en desarioIlo, los cuales han pasado a adquirir una importancia creciente para la recuperación de los países industrializados. La participación de los países en desarrollo en la industrialización mundial dependerá en buena medida de la forma que adopte el proceso de redistribución industrial en el futuro ${ }^{19}$.

\section{Las presiones sobre el equilibrio ecológico}

Aunque tal vez el punto central en que se produce el quiebre del estilo de desarrollo prevaleciente en la postguerra pasa por la in-

${ }^{18} \mathrm{~A}$. Lewis, "The evolution of the international economic order", 1979.

"OVer M. Olson, "The Rise and Decline of Nations", 1982, y M. Beenstock, "The World Economy in Transition", 1983. También W. Diebold Jr., "Industrial Policy on our International Issue", 1980; R. Müller, "Revitalizing America", 1980, y J. Pinder (ed.) "National Industrial Strategies and the World Economv", 1982. Sobre este tema ha vuelto A. Gunder Frank, en "La Crisis Mundial", 1980. Desde un punto de vista más amplio, ver E. V. Iglesias, "La crisis económicá internacional y las perspectivas de América Latina", en "Estudios Internacionales $N^{\circ}$ 62, abril-junio de 1983, y C. Furtado, "L'incertaine togique de la crise", en Le Monde Diplomatique No 347, febrero de 1983. 
dustria, no debemos olvidar que las primeras señales de que había llegado a su término el ciclo expansivo de los centros provinieron de Ios desequilibrios a que se vio sometida su base ecológica, tanto como resultado de la dinámica misma de ese estilo como de la emergencia de una serie de problemas globales aún no resueltos. Entre ellos cabe anotar el crecimiento de la población mundial; los diversos factores que limitan el crecimiento de la producción de alimentos; la incertidumbre y los mayores costos vinculados con el abastecimiento de energía y otras materias primas industriales; los problemas planteados por la excesiva concentración del crecimiento industrial en unas pocas áreas geográficas; la amenaza de la contaminación ambiental, generada fundamentalmente por el alto grado de concentración de la población urbana y de las actividades económicas, y otros problemas similares. Comienza a reconocerse, asi, que el ritmo y grado de concentración del crecimiento en los grandes centros industriales tuvo lugar a expensas del medio ambiente, la dotación de recursos naturales y la capacidad de sustentar ecológicamente ciertas actividades productivas.

Uno de los elementos que hay que tomar en cuenta, por lo tanto, para construir los escenarios en que se desenvolverán nuestras sociedades en los próximos decenios, se refiere a la existencia de límites ecológicos o físicos al crecimiento de las sociedades industriales $y$, probablemente, de la humanidad en su conjunto. Durante el decenio de 1970 se puso término al periodo de expansión sin precedentes de que disfrutó la humanidad durante la postguerra. El crecimiento económico, desde entonces, amenaza con rebasar la capacidad de absorción del ecosistema, comprometiendo así el delicado equilibrio ecológico que constituye la base de sustentación del desarrollo, mientras que la economía mundial pasa a caracterizarse por una situación de inseguridad en el abastecimiento de energía y de otras materias primas estratégicas. De allí que a lo largo del último período no haya cesado de profundizarse la conciencia de que el crecimiento económico tiene ciertos límites de carácter físico. El primer informe publicado bajo los auspicios del Club de Roma sobre esta problemática contribuyó a iniciar un debate que generó una pluralidad de reacciones en el plano teórico, mientras que las decisiones adoptadas por la opep en 1973 dieron la señal de alarma en el plano de las realidades ${ }^{20}$. El hecho de que las presiones generadas por el proceso de crecimiento económico sobre el equilibrio ecológico sean mucho más intensas en los países industrializados que en los paises en desarrollo, e impongan limitaciones mucho más severas a los primeros, puede tener importantes implicaciones

20D. H. Meadows et al., "The Limits to Growth", 1972. Ver también E. J. Mishan, "The Economic Growth Debate", 1977; K. D. Wilson, "Prospects for Growth: Changing expectations for the Future", 1977; V. Leontieff, "El Futuro de Ia Economia Mundial", 1977, y C. Freeman y M. Jahoda, "World Futures: the Great Debate", 1978. 
desde el punto de vista del papel que estos últimos-particularmente los países latinoamericanos- están llamados a desempeñar en la economía mundial.

El decenio de 1970 marcó el fin de una era caracterizada por un prolongado período de crecimiento de los centros industriales, basado en un suministro abundante y barato de energía y dependiente de un producto no renovable, como el petróleo. La circunstancia de que, como consecuencia del estilo de clesarrollo prevaleciente en los centros industriales, la demanda energética tendiera a crecer más rápidamente que la producción de estos recursos -unido al recrudecimiento de las tensiones planteadas en el Oriente Medio dentro de un escenario de mayor fluidez internacional- hizo que los países exportadores de petróleo utilizaran su organización con el fin de ejercer presiones eficaces para elevar los precios de ese combustible. Todo indica que, sin el dramatismo del decenio pasado, éstos seguirán elevándose, con diversos altibajos, hasta alcanzar niveles que permitan incorporar al uso económico fuentes alternativas de energía cuya operación es más costosa. Esa tendencia continuará presionando sobre las balanzas de pago de los países importadores de petróleo, y multiplicando sus requerimientos de inversión para desarrollar nuevas fuentes convencionales o alternativas de energía, programas que se elevarán de alrededor de 12.000 millones de dólares anuales a mediados del decenio pasado a 50.000 y 80.000 millones durante el primer y segundo quinquenios de los años 1980, respectivamente, tan sólo en el caso de América Latina. Todo ello crea un fuerte interés internacional, tanto de parte de los países desarrollados como en desarrollo, en torno a 1) el descubrimiento y difusión de tecnologías que permitan la conservación de energía, 2) la puesta en común de tecnologías que permitan incorporar fuentes nuevas y renovables de energía, particularmente en Ios países en desarrollo; y 3) del financiamiento de los desequilibrios de balanzas de pago requerido para mantener los mercados de los países importadores de petróleo y de las inversiones necesarias para incrementar su oferta energética ${ }^{21}$.

Las tendencias demográficas mundiales y su diferenciación según las distintas regiones, constituyen otro de los signos que es necesario leer para comprender el futuro. Desde luego, en el largo plazo, estas tendencias pueden ser consideradas como una variable exógena, dominada por factores naturales o biológicos que evolucionan independientemente de las transformaciones producidas dentro de la sociedad en su conjunto. De hecho, se trata de una variable cuya influencia en la configuración del futuro no puede ser apreciada aisladamente, sino en conjunto con otros factores incluidos en estas notas. La historia muestra la existencia de una estrecha co-

"Ver la sección sobre energla de "Las relaciones económicas externas de América Latina en los años 80", CEPAL, 1981. 
rrelación entre los cambios sociales y las tendencias demográficas. Estas últimas no han perdido toda la importancia que se les atribuyó a comienzo de Ios años setenta. Una de las diferencias entre las apreciaciones prevalecientes en esa época y las que predominan ahora, de mucha importancia desde el punto de vista del papel de los países en desarrollo en el futuro, radica en que la preocupación por el ritmo de crecimiento global de la población mundial ha sido complementada por una comprensión más desagregada acerca de sus tendencias por regiones y países. Así, mientras la participación de la población de los países de la OCDE declinará entre el 20 y el $15 \%$ hacia fines del presente siglo -y lo harán también la Unión Soviética y Europa del Este-- se incrementarán notablemente la de América Latina, Africa y Asia (y en menor medida la de China). Esto es importante, porque el balance o pugna entre población y recursos naturales se da al interior de las sociedades nacionales. Lo es también desde el punto de vista de las relaciones internacionales, en la medida en que las presiones demográficas provenientes de los países cuya población crece más rápidamente tienden a propagarse con más intensidad en un mundo interdependiente, lo que da lugar, entre otras cosas, a crecientes y cada vez más conflictivos movimientos migratorios. Lo es, por último, si se considera que la estructura de edad de las distintas sociedades nacionales tendrá una profunda influencia sobre la forma en que éstas se relacionen entre ellas, por cuanto las expectativas de generaciones jóvenes tenderán a proyectarse sobre la evolución de los demás países. El grueso de las generaciones jóvenes se concentra en los países en desarrollo. Entre ellas, las que tienen mayores posibilidades de proyectar sus expectativas sobre el resto del mundo son las que viven en países que han alcanzado una etapa de desarrollo intermedio, como los de América Latina.

\section{El sindrome finan,ciero}

Las transformaciones experimentadas por la división internacional del trabajo y la lentitud con que algunos países industrializados están encarando la reestructuración industrial requerida para adaptarse a ese nuevo esquema se ha traducido en un prolongado ciclo recesivo, en la aceleración de la inflación, y en un incremento explosivo de la deuda. En el fondo, todas las manifestaciones señaladas aparecen dominadas por este último fenómeno, que pasa a tener así una importancia decisiva en la crisis actual de la economía mundial22.

20obre este tema hay una frondosa literatura. Resulta hoy curioso releer de W. Robichek "Algunas reflexiones sobre el manejo del endeudamiento público externo", 1980. Ver al respecto $R$. Devlin, "Los bancos comerciales y el desarrollo de la periferia", en revista de la CEPAL $N^{\top} 9$ 9, 1979, y "La banca privada internacional en América Latina", en Cono Sur, febrero de 1983. Ver también 
Para examinar este fenómeno y sus perspectivas a largo plazo hay que comenzar por reconocer que, aunque las políticas adoptadas por los distintos países hayan tenido que ver mucho con la magnitud y forma de su impacto interno, el síndrome financiero que acompaña a la crisis tiene un origen predominantemente internacional. Se origina, en efecto, en una actitud de permisividad financiera sin precedentes por parte de los bancos privados internacionales, estimulada por las políticas monetarias reactivadoras adoptadas por algunos países industrializados, y alentada por la menor demanda de créditos por parte de estos mismos países, como consecuencia de la propia crisis, la necesidad en que se encontró la banca privada de jugar un papel fundamental en el reciclaje de los excedentes fínancieros acumulados por los países de la oper después de 1974, y la tendencia de esos mismos bancos a diversificar sus riesgos tornando elegibles a clientes que antes no lo eran.

Una consecuencia central de este fenómeno radica en la creciente participación de los bancos privados internacionales en el financiamiento externo de los países en desarrollo y en la consiguiente "privatización" de la deuda externa de estos últimos. El volumen de recursos movilizados por la banca privada relegó a un tercer plano el papel de las instituciones financieras internacionales de carácter público. Así, por ejemplo, los financiamientos del fondo monetario internacional, que a la fecha de su fundación equivalian al $16 \%$ del valor del comercio mundial, hoy sólo equivalen al $3 \%$ de éste. La participación de la banca privada en la deuda externa. total de América Latina subió de niveles muy modestos, a fines de los años sesenta, a una participación cercana al $80 \%$ a comienzos de la presente década.

La estrategia de endeudamiento externo seguida por los países latinoamericanos durante ese período, pareció razonable en la medida en que aquellos créditos eran otorgados en condiciones muy flexibles, con tasas de interés real negativas o muy bajas, y a plazos prolongados. De hecho, esa estrategia permitió paliar por algún tiempo los efectos de la recesión mundial sobre los países latinoamericanos, e hizo posible que durante la mayor parte del pasado decenio éstos crecieran a un ritmo bastante superior al de los países industrializados. Al mismo tiempo, durante la década de 1970 los países latinoamericanos constituyeron un mercado muy dinámico para los productos de los países desarrollados, contribuyendo significativamente a mantener el ritmo de la actividad económica mundial. Debe tenerse presente que durante ese decenio los países en desarrollo, en su conjunto, adquirieron alrededor de una tercera

R. Ffrench-Davis, "Deuda externa y balanza de pagos en América Latina", así como C. Massad, "La deuda externa y las politicas nacionales", ambos en Estudios Internacionales $N 962$, dedicado a la UNCTAD II y América Latina, abriljunio de 1983 . 
parte del incremento marginal de las exportaciones de los países industrializados. De paso, los nuevos mercados financieros internacionales generaron una alta tasa de ganancia para la banca privada en estos últimos.

Sin embargo, los propugnadores de estas estrategias subestimaron el riesgo de que una política desaprensiva a este respecto elevara los costos del servicio de la deuda por encima de la capacidad de pago a corto plazo de sus países, tornando la permisividad que hasta entonces había mostrado la banca internacional en fuerte cautela e inaugurando un período de encarecimiento y restricción del crédito. Ante todo, debe reconocerse que las condiciones en que éstos fueron otorgados no sólo presentaban aspectos ventajosos sino también negativos. Primeramente, el costo de esos créditos era variable, dependiendo de los agudos y frecuentes vaivenes de la tasa de interés. Segundo; los plazos de amortización de dichos créditos estuvieron sujetos también a fuertes variaciones, aumentando las posibilidades que los deudores experimentaran graves problemas de flujo de caja. Tercero, a lo largo de todo ese período, los mercados financieros internacionales adolecieron de una sorprendente falta de regulaciones, en contraste con lo que ocurría en los distintos países bajo la supervisión de las autoridades monetarias nacionales. Y la propia banca privada internacional, frente a la crisis, dio muestras de un alto grado de inestabilidad y de una gran falta de visión de largo plazo, al reducir el volumen de los créditos, acortar los plazos y aumentar sus costos en comisiones e intereses, en momentos en que los países deudores atravesaban por dificultades económicas.

Urge reconocer que la actual situación se debe ante todo, y por encima de la responsabilidad que pudiere atribuirse a las políticas de los países deudores en esta materia, a la conducta poco coherente de las fuentes privadas de financiamiento, agravada por la falta de instrumentos adecuados para abordar problemas de esta magnitud por parte de los organismos financieros internacionales. Urgè reconocer también que, en la medida en que actualmente todos los países del mundo se ven afectados por la recesión internacional y, al mismo tiempo, se requiere de la contribución de todos para promover la reactivación económica mundial, el problema deja de ser individual o regional, y pasa a convertirse en un problema global, que exige soluciones igualmente globales.

"Acreedores y deudores se encuentran así atados en un mismo sistema en donde cualquier desastre para una de las partes significará la ruina para tođos -declaró recientemente Kissinger en la Revista Newsweek-. Los acreedores no pueden suspender los créditos a sus deudores sin arriesgarse a enfrentar, no sólo un desastre bancario, sino también una profundización del proceso recesivo. Nuestro objetivo real debe apuntar a promover el crecimiento sostenido de.los patses en desarrollo; sin éste, las más frenéticas rene- 
gociaciones de la deuda externa se limitarán a dilatar la inevitable crisis".

El sistema financiero internacional en el futuro deberá reconocer que el servicio de la deuda debe supeditarse a las perspectivas de desarrollo de los países deudores y a las exigencias de la reactivación económica mundial; que el otorgamiento de nuevos créditos internacionales tendrá que sujetarse a nuevas condiciones que satisfagan esos objetivos, y enmarcarse dentro de una nueva condicionalidad, que debería ser negociada conjuntamente por acreedores y deudores; y que será necesario adecuar los organismos financieros internacionales para que puedan velar efectivamente por mantener la compatibilidad que debe existir entre el financiamiento internacional y los requerimientos del desarrollo.

Para que la creación de un nuevo sistema financiero internacional inspirado en esos criterios sea viable se requieren, además de voluntad política, tres condiciones. La primera consiste en la vigencia de un ambiente económico internacional libre de tendencias negativas importantes, que puedan disminuir la capacidad de pago de la deuda de los páses en desarrollo o aumentar intolerablemente el peso del servicio de la misma, y además que subsidiariamente las instituciones financieras internacionales dispongan de instrumentos adecuados para corregir temporalmente estas situaciones si el ambiente económico internacional se torna muy desfavorable. Desde el punto de vista interno, los países deudores deberían cuidar de que los recursos de origen externo que obtengan del sistema financiero internacional se destinen a ampliar la capacidad productiva del país y, por lo tanto, su capacidad de pago futuro de la deuda, conjuntamente con el ahorro interno -en el lugar de sustituir ahorro nacional, y destinarse a actividades introductivas o a inversiones de baja rentabilidad o de muy largo plazo, como ha ocurrido en varios países de América Latina. Por último, será necesario también que la disposición de los banqueros privados para mantener un determinado volumen de financiamiento externo a sus deudores no sufra bruscas variaciones: para ello, por una parte, deberían evaluar más cuidadosamente desde el inicio el riesgo de sus operaciones $y$, por la otra, deberían trabajar en contacto más estrecho con los propios deudores, con las autoridades monetarias de s'us respectivos países y con las instituciones financieras internacionales. $\mathrm{La}$ actual crisis financiera mundial permite anticipar con bastante certidumbre que en el futuro el manejo del sistema dependerá del grado de coordinación y compromiso que exista entre estos tres niveles, a saber, la banca privada internacional, las autoridades monetarias internas y las instituciones financieras internacionales. $Y$ dependerá también, como se ha dicho, de un permanente y más estrecho entendimiento entre los acreedores y deudores, basado en el reconocimiento de que el sistema financiero internacional debe 
estar al servicio del desarrollo y de la actividad económica mundial, que constituyen la condición misma de su supervivencia.

Dentro de este contexto, será esencial reafirmar el vínculo entre el comercio y el financiamiento, fuertemente dibilitado por el deterioro que han experimentado los términos de intercambio de los productos de exportación de los países latinoamericanos durante los últimos años, por la intensidad y modalidades que ha adoptado el proteccionismo en los países desarrollados y por la erosión que, en general, han sufrido las reglas que regian el sistema de comercio internacional, dando paso a una situación en que los principios de libre comercio que inspiraron los acuerdos de Bretton Woods han sido reemplazados por modalidades de comercio "administrado" $\mathrm{q}$ "compensado", entronizadas en forma unilateral o bilateral por los países industriales ${ }^{28}$.

\section{EL DESAFÍO A LAS ORGANIZACIONES REGIONALES LATINOAMERICANAS}

Los países latinoamericanos tienen una larga tradición de concertarse para actuar tanto en el escenario regional como en el contexto externo, tradición que naturalmente incluye relaciones de cooperación y de conflicto, y que ha dado lugar periódicamente a la creación o reemplazo de una serie de organizaciones regionales que están llamadas a desempeñar un papel importante en el fortalecimiento de la cooperación y la capacidad de acción concertada entre los países latinoamericanos. Esta sección parte del supuesto de que esía tradición es necesaria para facilitar el logro de la paz y el desarrollo dentro de la región, incrementar el poder de negociación externa de los países latinoamericanos y preservar su identidad económica, política y cultural dentro de márgenes de autonomia razonablcs.

En los últimos años, èl movimiento hacia la unidad latinoamericana ha sufrido serias resquebrajaduras, como consecuencia de fuertes presiones derivadas de factores económicos, políticos o estratégicos, tanto de origen intra como extra regional. Podría decirse que, a partir de la postguerra, nunca había habido un predominio tan claro de las fuerzas centrífugas en América Latina.

Dentro de esta preocupeción por construir algunos de los escenarios en que probablemente se desenvolverá la región en los próximos decenios, resulta indispensable analizar las limitaciones que presentan las organizaciones regionales para enfrentarlos, y sugerir

20r UNCTAD, "Trade and Development Report 1982". Asimismo, W. Hager, "El comercio Norte_Sur y la autonomía socio-económica: una fórmula de paz", y R. Figueiredo, "Hacia una nueva apreciación del sistema de comercio internacional", ambos en Estudios Internacionales No 62, abril-junio de 1983. Un punto de vista inquietante es planteado por $F$. Kitamura en "Free trade vs. proteccionism: Trade policy issues in a new perspective", North South Round Table, 1982. 
algunos de los lineamientos de conformidad con los cuales estas organizaciones deberían ser reestructuradas.

Nos referimos, a continuación, a los tres grandes marcos en que se han venido desenvolviendo las relaciones externas de los países latinoamericanos durante la postguerra, a las organizaciones creadas dentro del ámbito de cada uno de ellos, y:a su crisis: el sistema interamericano, los foros globales y los organismos estrictamente regionales.

\section{El debilitamiento del sistema americano}

Desde fines de la segunda guerra mundial, las relaciones internacionales de América Latina quedaron determinadas por un hecho fundamental: el estallido de la guerra fría y su supeditación a los Estados Unidos, a través de su. firme adscripción a las instituciones que configuraban el sistema hemiférico. Durante cerca de veinte años estas instituciones cumplieron su papel relativamente bien, y las relaciones externas de los países latinoamericanos quedaron completamente mediatizadas por ellas. Así lo reconoce muy gráficamente la siguiente declaración tomada al azar de entre un cúmulo de testimonios referentes a esa época.

"América Latina no es, en el análisis final, de una importancia de vida o muerte para los Estados Unidos, ya sea estratégica, política, económica o ideológicamente. América Latina bien puede valer una misa, pero no vale una dedicación masiva de recursos económicos, energía política o atención militar. Por sí misma, América Latina no puede ir a ninguna parte, es un lugar 'estratégicamente solitario'; y si comenzara a ir a alguna parte bajo las directivas de alguna otra gran potencia (la Unión Soviética), entonces los Estados Unidos tratarían con esa otra gran potencia y no con América Latina"24.

En el plano político, esa intermediación se efectuó a través de la Organización de Estados Americanos (OEA), tal como se estructurara después de la Conferencia de Bogotá, en 1948, y de su instrumento militar, el Tratado Interamericano de Asistencia Recíproca (TIAR), tristemente célebre por haber servido de modelo para la adopción de los demás tratados defensivos con que John Foster Dulles intentó tender un "cordón sanitario" en torno a Ghina a lo largo del gigantesco arco que separa a Irán de Ias Filipinas. El sistema hemisférico sólo extendió sus actividades al ámbito del desarrollo económico con gran reluctancia y en forma tardía, después que los Estados Unidos rechazaran reiteradamente las demandas for-

${ }^{21}$ Declaración formulada por el Sr. John N. Blake, de la Brookings Institution y de la Universidad de Connecticut, ante el Consejo de Relaciones Exteriores de los Estados Unidos, citada en la Revista Punto Final No 180, Santiago de Chile, 19 de febrero de 1972. 
muladas por los países latinoamericanos en tal sentido, con la puésta en marcha del Banco Interamericano de Desarrollo (BID) en 1960 .

La vigencia de estas instituciones se basaba en la situación de América Latina como "Iugar estratégicamente solitario" y en su confinamiento al ámbito hemisférico, que mediatizaba sus vínculos externos, todo lo cual implicaba la existencia de una fuerte "relación especial" con los Estados Unidos. El fin de esa "relación especial", como consecuencia de las tendencias señaladas en la sección precedente, hizo posible que las relaciones externas de los países latinoamericanos se diversificaran apreciablemente, proyectándose tanto hacia el escenario regional como hacia el resto del mundo, a lo largo de un arco mucho más amplio que en el pasado. Ello debilitó profundamente la validez y efectividad de las organizaciones interamericanas ${ }^{25}$.

El sistema interamericano se basaba en tres premisas cuya validez fue erosionada profundamente por las tendencias mencionadas más arriba. La primera se refería a la necesidad de que América Latina permaneciese adscrita a un sistema de seguridad hemisférico como única manera de asegurar su defensa contra el enemigo común del mundo libre bajo el esquema de la guerra fría. La segunda presumía la existencia de una especie de "armonía natural de intereses" entre los Estados Unidos y América Latina; tanto en 10 referente a la seguridad de estos países como en materias económicas. La tercera se basaba en el reconocimiento de que, dentro de esta alianza, el liderazgo y la iniciativa debían corresponder naturalmente a los Estados Unidos.

A la luz de los cambios ocurridos en los escenarios mundial y latinoamericano, todas estas premisas resultaron ser falsas y disfuncionales, convirtiendose en fuentes de innumerables mal entendidos y frecuentes fricciones. La supeditación de América Latina a un esquema basado en el concepto de la guerra fría ha distorsionado sistemáticamente las interpretaciones oficiales acerca de las reivindicaciones políticas, sociales o económicas de los países latinoamerica nos y de sus sociedades $y$, en los últimos años, ha transferido hacia la región explosivos conflictos que se inscriben dentro de las relaciones Este-Oeste, como ocurre con las guerras civiles que se están generalizando en 'Centroamérica, o con-las tensiones que se están desarrollando en el área del Caribe. La pretendida "armonía natural de intereses" entre los dos segmentos del sistema hemisférico fa-

"Sobre el "fin de la relación especial" con los Estados Unidos, mencionada más arriba, ver de L. Tomassini "Us-Latin American Relations in a Changing International Framework", documento presentado a la New World Conference, realizada en San Antonio, Texas, en noviembre de 1975, y publicado en Hemispheric Perspectives on the United States, por J. S. Tulchin (editor), 1978. Ver también el difundido artículo de Abraham Lowenthal titulado "The United 
voreció, de hecho, una creciente presencia de intereses estadounidenses en los mercados y empresas latinoamericanos, postergó un análisis franco y una negociación realista en torno a muchos temas y sirvió de escuela en donde los Estados Unidos aprendieron a mantener una actitud que oscila entre la prescindencia y el obstruccionismo en los grandes foros internacionales - ya se trate de las negociaciones globales, la UNCTAD o la Conferencia sobre el Derecho del Mar- en abierta contradicción con sus responsabilidades mundiales. El hábito de aceptar la tutela estadounidense en todas las cuestiones importantes relacionadas con su política exterior, creó problemas cada vez que los países latinoamericanos procuraron tomar la iniciativa, a fin de aprovechar las condiciones de un contexto internacional más permisivo, comenzando por la política nacionalista del gobierno militar peruano en 1968 y terminando con el conflicto armado entre Argentina y Gran Bretaña en 1982 -sin olvidar una serie de dilemas que incluyen los convenios germano-brasileños sobre la adquisición de reactores nucleares o los entendimientos entre algunos países europeos y centroamericanos en torno a la naturaleza y posibles soluciones del conflicto planteado en esa subregión. En último término, esta tutela -y su lógica consecuencia: un bilateralismo selectivo- debilitó la identidad propia de América Latina, un fenómeno cuya última manifestación se dio en el caso del conflicto de las islas Malvinas.

"Independientemente de la crisis de las Malvinas -expresa un prestigioso analista en una publicación reciente consagrada a este tema- el formato adoptado para regular las relaciones interamericanas en la década del cuarenta se volvió manifiestamente inadecuado en la del setenta y simplemente inviable en la década actual. El gran desarrollo de los países latinoamericanos a partir de los años cincuenta, especialmente de los países mayores de la región, modificó significativamente la estructura de sus relaciones con los Estados Unidos y con el mundo en general. Por otro lado, se añade a eso que la posición relativa de los Estados Unidos en el mundo también sufrió profundas transformaciones en ese período. El centro dinámico de la economía se desplazó hacia la faja Europa-Japón... La crisis de las Malvinas vino a poner en evidencia la inadecuación del sistema interamericano, que se fuera acentuando en el curso de un largo proceso, para regular las relaciones entre los Estados Unidos y los países de América Latina. La decisión por parte de los Estados Unidos de ignorar el TIAR en el episodio de las Malvinas y de asumir finalmente una posición de declarado apoyo logístico (a Gran Bretaña) deshizo el mito de la solidaridad continental. Así, perderían vigencia las suposiciones en que se fundaba

States and Latin America: Ending the Hegemonic Presumption", publicado en Foreign Affairs, Vol. 55, No 1, October 1976. 
el sistema interamericano, con la OEA (solidaridad continental) y el TIAR (enemigo externo común) "26.

\section{Inoperancia de los foros globales}

Como ya he señalado, el debilitamiento de la "relación especial" con los Estados Unidos y la erosión de las instituciones que conforman el sistema interamericano estimuló la diversificación de las relaciones externas de los países de la región tanto en el ámbito mundial como latinoamericano, sin contribuir sensiblemente a fortalecer los organismos multilaterales establecidos para canalizar dichas relaciones. En ellas predominó también un marcado bilateralismo, esta vez de inspiración latinoamericana.

América Latina tuvo un papel preponderante en la gestación de las ideas y las instituciones que han enmarcado las negociaciones entre los países industrializados y los países en desarrollo a lo largo de los últimos veinte años. "Guando América Latina planteó la necesidad de realizar un examen crítico de las relaciones centro-periferia, principalmente a través de los análisis de D. Raúl Prebisch y de sus primeros colaboradores en la Comisión Económica para América Latina de las Naciones Unidas (CEPAL), no había prácti. camente nadie que desde una perspectiva no marxista cuestionara el orden internacional enraizado en el desarrollo y ulterior liqui. dación de los imperios coloniales y consagrado, hacía pocos años, en Ios acuerdos de Bretton Woods. Eventualmente, el pensamiento latinoamericano, acuñado en la GEPAL (a comienzos de los años cincuenta), alcanzó resonancia mundial a través de la UNCTAD y condujo a un cuestionamiento generalizado del orden establecido. Sin embargo, paradojalmente, hoy parece darse una situación inver. sa: los planteamientos referentes a la necesidad de un nuevo orden internacional provienen de otras regiones del mundo en vías de desarrollo -o de países industrializados que tienen como marco de referencia las características y problemas de sus antiguas esferas de influencia y que están muy poco familiarizados con la realidad latinoamericana- mientras que en América Latina se hace sentir la falta de un análisis crítico y de una respuesta propia frente a estos planteamientos"27.

${ }^{30}$ Helio Jaguaribe, "Reflexiones sobre el Atlántico Sur: América Latina y el Brasil ante la Desarticulación del Sistema Interamericano", en Estudios Internacionales $\mathrm{N}^{0} 60$, octubre-diciembre de 1982, edición monográfica titulada América Latina después de las Malvinas. Las citas están tomadas de las páginas 444 y 4.54 .

æT. Tomassini, "Falenrias y Falacias: Notas sobre el Estudio de las Relaciones Norte-Sur", en Estudios Internacionales No 40, octubre-diciembre de 1977, p. 112. Para una visión crítica acerca de la posición de América Latina en las negociaciones Norte.Sur y del papel que han jugado en ellas los respectivos foros, ver entre otros trabajos, "Factores Ambientales, Crisis en los Centros y Cambio en las Relaciones Internacionales de los Paises de la Periferia, en Re- 
El programa de acción propuesto por el tercer mundo para el establecimiento de un Nuevo Orden Económico Internacional adolece de una serie de debilidades que conspiran contra su viabilidad. $\mathrm{Su}$ primera y más fundamental limitación radica en todas las medidas incluidas en dicho programa tienden a promover una transferencia unilateral de recursos desde los países desarrollados hacia los países en desarrollo, sin dejar ningún espacio para la identificación de los intereses mutuos que vinculan a ambos grupos de países, al menos en algunos sectores. Lo anterior se debe, en segundo lugar, a que este programa está integrado casi exclusivamente por el listado de los problemas que aquejan a los países en desarrollo, prestando escasa consideración a las tendencias observables en los centros y a la evolución de la economía mundial en su conjunto. Atenta contra su eficacia, en tercer término, su carácter excesivamente intemporal o estático y su falta de flexibilidad para adaptarse a las cambiantes oportunidades o exigencias de la economía internacional. En cuarto lugar, muestra una marcada predilección por la adopción de medidas excesivamente generales, como el Sistema Generalizado de Preferencias o el Programa Integrado de Productos Básicos, cuya implementación ha demostrado ser ardua y frustrante. En quinto lugar, presupone la existencia de una homogeneidad básica entre los países en desarrollo, lo cual está en contradicción con la tendencia registrada en los últimos años hacia una creciente diferenciación al interior de esos países.

En efecto, a partir del decenio pasado, es posible distinguir entre ellos, a lo menos, tres categorías de naciones: los países miembros de la OPEP, los países que están atravesando por un rápido proceso de industrialización o que han alcanzado una etapa de desarrollo intermedio, y los de menor desarrollo relativo, que configuran el llamado cuarto mundo. Es por lo demás evidente que aún dentro de cada una de esas categorías de países es posible formular otras distinciones. Lo anterior exige reconocer que, más allá de la básica identidad que presentan los problemas y las aspiraciones de los países en desarrollo y de la consiguiente necesidad de mantener la solidaridad del Sur en sus negociaciones con el Norte, cada una de estas categorías posee intereses, objetivos y prioridades propias. La falta de reconocimiento de esta realidad tiende a imprimir a las posiciones de los países en desarrollo un carácter retórico y a provocar un divorcio entre los planteamientos efectuados en los foros multilaterales, ya sea en Ginebra, Nueva York o Bruselas, y las acciones concretas emprendidas desde sus capitales.

Estas faltas se deben, en buena medida, al debilitamiento del li-

vista de la cEPAL No 12, diciembre dè 1980". así como también "Las Negociaciones Norte-Sur: Algunas Alternativas", en el Trimestre Económico No 194, Mé. xico, abril-junio de 1982. Ver también El Diálogo Norte-Sur: Una Perspectiva Latinoamericana, libro editado por el mismo autor en Buenos Aires, 1982. 
derazgo intelectual de América Latina en los foros internacionales. A su vez, ésta se originó en la pérdida de la capacidad de concertación que en el pasado mostraron los países latinoamericanos, capacidad que les permitió analizar desde una perspectiva comúr sus relaciones económicas externas, y llevar posiciones conjuntas a los grandes foros internacionales.

\section{De la integración económica a la seguridad regional latinoamericana}

La integración económica latinoamericana experimentó un avance apreciable durante los veinte años que siguieron a 1960; época en que se establecieron los primeros esquemas de integración, pero en general estuvo muy lejos de alcanzar el dinamismo que se le había atribuido cuando se iniciaron dichos movimientos. A lo largo de esos veinte años el comercio intrarregional, expresado en las exportaciones, se multiplicó en más de diez veces y su participación en el comercio total pasó de poco más de $8,5 \%$ a cerca del $16 \%$ en dicho periodo. Sin embargo, como ha señalado más arriba, tal vez el principal impulso a la integración provino de acciones parciales de cooperación realizadas por dos o más países, con base en acuerdos o proyectos específicos, y emprendidas generalmente al margen de los esquemas formales de integración que funcionaban en el área, a saber, la Alala, el Mercado Común 'Centroamericano, CaRICom y el Pacto Andino. Estos esquemas experimentaron una considerable erosión durante ese período o al menos quedaron muy lejos de las expectativas que se habían depositado en ellos.

Ello se debió en parte a la insuficiencia intrínseca a tales esquemas, y en parte también a que a partir de los años setenta estos mecanismos estuvieron sujetos a grandes tensiones, derivadas tanto de las turbulencias provenientes del contexto internacional como del cambio en las estrategias de desarrollo de algunos países latinoamericanos. Por otra parte, estos mismos factores de inestabilidad e incertidumbre explican la posición adoptada por la mayoría de los gobiernos del área en el sentido de evitar compromisos rígidos, y de conservar la mayor libertad posible para instrumentar sus polfticas económicas externas. Ello, a su vez, redundó en la tendencia a flexibilizar los esquemas de integración existentes o a buscar nuevas modalidades de cooperación al margen de ellos. De estas tendencias resultó, entre otras cosas, la creación del SELA y de la AlADr, cuya eficacia aún tiene que ponerse a prueba.

Durante el decenio de 1970 hubo, pues, una estrecha relación entre los cambios ocurridos en el contexto económico internacional -particularmente en lo referente a la extraordinaria ampliación y al dinamismo que mostraban los mercados financieros y comerciales internacionales durante los años 1970- y el cambio experimer- 
tado por las estrategias de desarrollo de un nủmero importante de latinoamericanos. Estos cambios no sólo se refieren a aquellos países que optaron por ensayar políticas exageradas de apertura externa, sino también a los que se valieron de la permisividad financiera internacional para impulsar internamente políticas expansivas poco razonables, incluyendo algunos países exportadores de petróleo. El fuerte impacto que turo la crisis económica internacional sobre América Latina después de 1980 curvó esas tendencias y proporcionó nuevos incentivos para mirar hacia el potencial de clecimiento y de cooperación existente dentro del ámbito regional ${ }^{28}$.

Entretanto, el conflicto del Atlántico Sur puso de manifiesto con más claridad que en el pasado algunos de los problemas que permanentemente han afectado las relaciones extermas de los países latinoamericanos. Permitió apreciar cómo un peligro que se había venido señalando hacía largo tiempo -el aumento de la vulnerabilidad externa de América Latina- llegó a adquirir dimensiones inaceptables, que colocan a esta región del mundo a merced de decisiones políticas, económicas y estratégicas al servicio de los intereses de las grandes potencias, cuya defensa es puesta invariablemente por encima de todo otro compromiso.

Es un hecho bien establecido que la incertidumbre ha pasado a constituir uno de los rasgos centrales del escenario internacional contemporáneo. La crisis de las economías desarrolladas ha golpeado con fuerza a los países latinoamericanos, magnificando los problemas que estructuralmente han obstruido su proceso de desarroIlo. Este impacto ha sido particularmente intenso e inmediato debido, por una parte, porque América Latina se ha integrado más estrechamente en la economía internacional $y$, por la otra, porque ésta se ha vuelto más interdependiente y ha generado mecanismos que actúan como poderosas poleas de transmisión de los fenómenos generados en los centros dinámicos hacia la periferia del sistema. Entre estos mecanismos de transmisión se cuentan la recesión que afecta a los países industrializados y la consiguiente reducción de sus importaciones; el recrudecimiento del proteccionismo, que li-

spara un análisis más pormenorizado de la evolución de estos procesos, ver, de L. Tomassini, "Elementos para un estudio de los procesos de integración y. cooperación en América Latina", en Comercio Exterior, México, enero de 197\%, y también "La integración y el cambio de las estrategias de desarrollo de los paises latinoamericanos", en M. Wilhelmy (ed.), Sociedad, Política e Integración en América Latina, 1982. Uno de los primeros aportes a la comprensión de estos cambios se encuentra en D. Shydlowsky, "Industrialization and Growth", en J. Einaudi (ed.), Beyond Cuba, 1974. Acerca de la tendencia hacia la "flexibilización de los procesos de integración, entre los primeros aportes de cEPAL ver "América Latina en el Umbral de los Años 80", 1976, pp. 167 y siguientes, así como más recientemente M. S. Wionczek, "La evaluación del tratado de Montevideo 1980 y las perspectivas de las acciones de alcance parcial en Ia ALADI", en Integración Latinoamericana No 50, septiembre de 1980. 
mita todavía más las exportaciones de los países de la periferia; 'la inflación registrada en los países centrales, que se propaga a la periferia a través del aumento de los precios de los bienes de capital y las manufacturas; la elevación de las tasas de interés; el aumento de los precios del petróleo; y, en general, la transferencia hacia estos últimos países de estilos de desarrollo acuñados en los grandes centros industriales que distorsionan sus procesos de crecimiento económico sujetándolos a rigideces indebidas, y atenúan su vulnerabilidad externa.

En el plano político cabe llamar la atención hacia la crisis de hegemonfa observable en el mundo desarrollado y la ausencia de elementos que pudieran fundamentar un nuevo "orden mundial" de carácter estable y más dinámico. AI mismo tiempo, el avance del proceso de transnacionalización genera una proliferación de juegos y de actores, en gran parte independientes de los gobiernos que persiguen una gran variedad de propósitos con consecuencias frecuentemente desestabilizadoras y siempre complejas. En suma, es notoria la ausencia de nuevas reglas para el manejo de las relaciones de los países desarrollados con el resto del mundo, particularmente con los países en desarrollo.

En el plano estratégico, el efecto disuasivo causado por la acumulación de armamentos nucleares con respecto a la posibilidad de que estallen conflictos entre las grandes potencias, la necesidad de dirimir los nuevos conflictos potenciales mediante el uso de recursos convencionales, Ia consiguiente fragmentación del teatro de las operaciones y el deseo de evitar la participación de las grandes potencias en ellos y de actuar a través de los llamados proxies, introducen en la palestra mundial a un creciente número de países y regiones en desarrollo, y acentúan su vulnerabilidad estratégica externa.

Todos estos factores de incertidumbre acentúan la crisis de los principales marcos dentro de los cuales los países latinoamericanos han conducido tradicionalmente sus relaciones internacionales, a los cuales nos habíamos referido más arriba. Desde luego, obligan a revisar las expectativas relacionadas con el diálogo Norte-Sur, teniendo en cuenta la reacción adversa de un número importante de países industrializados frente a las aspiraciones de los países en desarrollo. Cuestionan, asimismo, los fundamentos sobre los cuales se construyó y ha funcionado hasta ahora el sistema interamericano. Finalmente, si bien ponen de relieve la importancia de la solidaridad latinoamericana, revelan al mismo tiempo su precariedad, planteando el desafío de avanzar más allá de motivaciones oportunistas y de gestos retóricos, para cimentarla sobre bases duraderas.

Al mismo tiempo, nunca se había puesto en evidencia de una manera tan patente como en los últimos años la vinculación existente entre el incremento de Ia "inseguridad externa" de los países 
latinoamericanos y la presencia de los llamados regímenes de "seguridad nacional" en muchos de ellos: Hoy podemos apreciar con claridad que esos regímenes han erosionado peligrosamente las bases de la estabilidad y la autonomía de estos países, de tal manera que hoy resulta evidente para amplios sectores que antes no lo veían el hecho de que la reconquista de esos valores pasa por el reestablecimiento de la democracia en América Latina. 